$$
\text { CONF- } 9605192--1
$$

\title{
Recent Studies on the Chemical Conversion of Energetic Materials to Higher Value Products
}

Alexander R. Mitchell

Philip F. Pagoria

Robert D. Schmidt

\section{RECEIVED \\ JUN 241996 \\ OSTI}

This paper was prepared for submittal to the

Fourth International Symposium on Special Topics in Chemical Propulsion

Stockholm, Sweden, May 27-31, 1996

May 1996

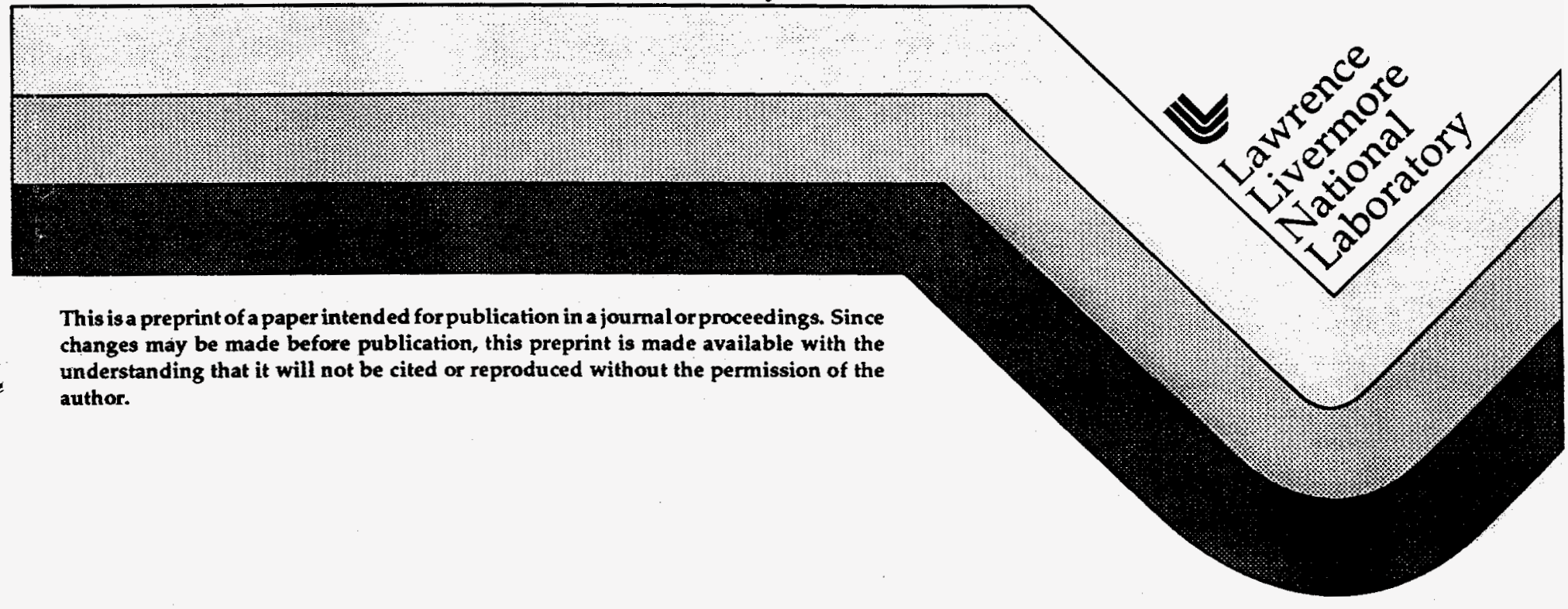




\section{DISCLAIMER}

This document was prepared as an account of work sponsored by an agency of the United States Government. Neither the United States Government nor the University of California nor any of their employees, makes any warranty, express or implied, or assumes any legal liability or responsibility for the accuracy, completeness, or usefulness of any information, apparatus, product, or process disclosed, or represents that its use would not infringe privately owned rights. Reference herein to any specific commercial product, process, or service by trade name, trademark, manufacturer, or otherwise, does not necessarily constitute or imply its endorsement, recommendation, or favoring by the United States Government or the University of California. The views and opinions of authors expressed herein do not necessarily state or reflect those of the United States Government or the University of California, and shall not be used for advertising or product endorsement purposes. 


\section{DISCLAIMER}

Portions of this document may be illegible in electronic image products. Images are produced from the best available original document. 


\title{
RECENT STUDIES ON THE CHEMICAL CONVERSION OF ENERGETIC MATERIALS TO HIGHER VALUE PRODUCTS*
}

\author{
Alexander R. Mitchell, Philip F. Pagoria, and Robert D. Schmidt \\ Energetic Materials Center, Lawrence Livermore National Laboratory \\ MS L-282, P.O. Box 808, Livermore, California 94550, USA
}

\begin{abstract}
The objective of our program is to develop novel, innovative solutions for the disposal of surplus energetic materials (high explosives, propellants) resulting from the demilitarization of nuclear and conventional munitions. Historically, energetic materials have been disposed of by open burning/open detonation (OB/OD) which is becoming unacceptable due to public concerns and increasingly stringent environmental regulations. The use of energetic materials as chemical feedstocks for higher value products potentially provides environmentally sound and cost-effective alternatives to $\mathrm{OB} / \mathrm{OD}$. The conversion of UDMH (unsymmetrical dimethylhydrazine, 1,1dimethylhydrazine) and Explosive $D$ (ammonium picrate) to higher value explosives such as 1,3,5-triamino-2,4,6-trinitrobenzene (TATB) and 1,3-diamino-2,4,6-trinitrobenzene (DATB) illustrates our approach. TATB is a reasonably powerful high explosive whose thermal and shock stability is considerably greater than that of any other known material of comparable energy. We have developed a new synthesis of TATB that can utilize surplus UDMH (propellant) and Explosive D (high explosive) as starting materials. Methyl iodide reacts with UDMH to provide TMHI $(1,1,1$ trimethylhydrazinium iodide) which serves as a reagent for the amination of nitroaromatic substrates via Vicarious Nucleophilic Substitution (VNS) of hydrogen. When TMHI is reacted with various nitro-substituted aromatics the amino functionality is introduced in good to excellent yields. The reaction of picramide (obtained from Explosive D) with an appropriate amount of TMHI in dimethylsulfoxide in the presence of a strong base ( $N a O M e$ or $t$-BuOK) gives TATB or DATB in $95 \%$ and $75 \%$ yields, respectively. This synthesis should offer significant savings in the production of TATB thereby making this insensitive high explosive more accessible for civilian applications. We are currently investigating the use of TMHI and other quaternary hydrazinium compounds derived from UDMH to prepare higher value products.
\end{abstract}

*Work performed under the auspices of the U.S. Department of Energy by Lawrence Livermore National Laboratory under Contract No. W-7405-ENG-48 


\section{Introduction}

The demilitarization of nuclear and conventional munitions is producing millions of pounds of surplus explosives (energetic materials). Historically, surplus explosives have been disposed of by open burning/open detonation (OB/OD). The disposal of these materials by $O B / O D$ is becoming unacceptable due to public concerns and increasingly stringent environmental regulations. Environmentally sound and cost-effective alternatives to $O B / O D$ are needed. We are investigating the chemical conversion of energetic materials to higher value products. This paper focuses on the use of a surplus propellant (UDMH) and high explosive (Explosive D) as chemical precursors to higher value explosives (DATB and TATB).

\section{TATB}

TATB is a reasonably powerful high explosive whose thermal and shock stability is considerably greater than that of any other known material of comparable energy. ${ }^{1}$ it is used in military applications because of its significant insensitivity to thermal and shock environments. There is also interest in employing TATB in the civilian sector for deep oil well explorations where heatinsensitive explosives are required. TATB had been priced at $\$ 20$ to $\$ 50$ per pound when it was being produced on an industrial scale in the U.S. TATB is currently available to customers outside of the Department of Energy (DOE) for $\$ 100$ per pound. 2 This paper describes a new synthesis of TATB developed at Lawrence Livermore National Laboratory (LLNL) that utilizes inexpensive starting materials and mild reaction conditions.

\section{Current Preparation of TATB}

TATB is produced in the USA by nitration of the relatively expensive and domestically unavailable $1,3,5$-trichlorobenzene (TCB) to give 2,4,6-trichloro-1,3,5-trinitrobenzene (TCTNB) which is then aminated to yield TATB (Scheme 1). ${ }^{3}$ Elevated temperatures $\left(150^{\circ} \mathrm{C}\right.$ ) are required for both reactions. The major impurity encountered in this process is ammonium chloride. The inclusion of<smiles>O=[N+]([O-])c1c(Cl)c([N+](=O)[O-])c(Cl)c([N+](=O)[O-])c1Cl</smiles>

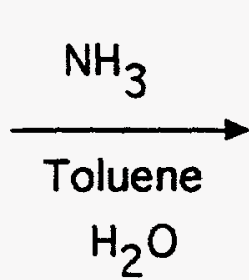<smiles>Nc1c([N+](=O)[O-])c(N)c([N+](=O)[O-])c(N)c1[N+](=O)[O-]</smiles>

Scheme 1. Current synthesis of TATB.

$2.5 \%$ water during the amination step significantly reduces the ammonium chloride content of the TATB. 4 Low levels of chlorinated organic impurities have also been identified. These impurities include 2,4,6-trichloro-1,3,5-trinitrobenzene (TCTNB), 1,3-dinitro-2,4,5,6-tetrachlorobenzene, 1,3-dinitro-2,4,6-trichlorobenzene and their partially aminated products. 5 A synthesis of TATB that replaces TCTNB with a non-chlorinated starting material is clearly desirable.

\section{Vicarious Nucleophilic Substitution of Hydrogen}

Vicarious nucleophilic substitution (VNS) of hydrogen is a well-established procedure for the introduction of carbon nucleophiles into electrophilic aromatic rings. 6,7 The reaction involves the addition of a carbanion bearing a leaving group $(X)$ to an electrophilic aromatic ring and subsequent rearomatization by loss of the leaving group through elimination as $\mathrm{HX}$ (Scheme $2, Z=\mathrm{CH}_{2}$ ). This reaction has been applied to a wide variety of nitroarenes and nitro-substituted heterocycles. 7 
<smiles>[R]c1cccc([N+](=O)[O-])c1</smiles>

$+\mathrm{X}-\mathrm{ZH}$

$\mathrm{Z}=\mathrm{CH}_{2}, \mathrm{NH}$<smiles>[R]C1=CC(=[N+]([O-])[O-])C=CC1[R]</smiles>

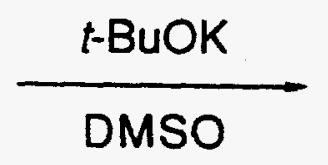<smiles>[R]C1=CC(=[N+]([O-])[O-])C=CC1[Z]</smiles><smiles>[Y][V]</smiles>

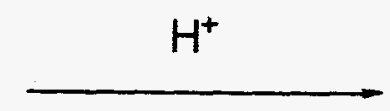<smiles>[Z]c1ccc([N+](=O)[O-])cc1[R]</smiles>

Scheme 2. Vicarious nucleophilic substitution of hydrogen.

By analogy, VNS reactions can also take place with amine nucleophiles. Such reagents are of the common form $X-\mathrm{NH}_{2}$, where $X$ is an auxiliary group capable of stabilizing a negative charge, thus driving rearomatization of the $\sigma$-intermediate adduct (Scheme 2, $Z=\mathrm{NH}$ ). One of the first examples of amination by VNS of hydrogen was provided by Meisenheimer and Patzig who reacted 1,3dinitrobenzene with hydroxylamine in the presence of strong base to yield 2,4-dinitrophenylene1,3-diamine. 8 Recently, a number of more active aminating reagents such as 4-amino-1,2,4triazole $^{9}$ and substituted sulfenamides 10 have been developed. These reagents were designed to be good nucleophiles that easily add to electrophilic aromatic rings and also possess good leaving groups (Scheme 2, $X=1,2,4$-triazole, RS).

\section{Use of 1,1,1-Trimethylhydrazinium lodide as a VNS Reagent}

Although quaternary hydrazinium compounds have been known for over one hundred years, 11,12 they have not been employed as VNS reagents. We examined 1,1,1-trimethylhydrazinium iodide (TMHI) ${ }^{13}\left[\left(\mathrm{CH}_{3}\right)_{3} \mathrm{~N}^{+}-\mathrm{NH}_{2} \mathrm{I}^{-}\right]$for use as a VNS reagent. We reasoned that TMHI would be sufficiently nucleophilic to substitute into nitro-substituted aromatic rings but would be superior to the previous examples because the leaving group would be the neutral trimethylamine instead of a stabilized anionic species. In addition, there was a possibility that the hydrazinium halide would react with base to form the neutral ylide species, $\left[\left(\mathrm{CH}_{3}\right) 3 \mathrm{~N}^{+}-\mathrm{NH}^{-}\right]$, which may be the reactive species in the amination process. Indeed, when TMHI was reacted with various nitro-substituted aromatics the amino functionality was introduced in good to excellent yields. We found that the number of amino-groups which may be added to the electrophilic aromatic ring was equal to the number of nitro groups present on the ring.

A study of product yields and distribution of various 3-substituted nitrobenzene derivatives was performed using TMHI (Scheme 3) (Table 1). 14 The results of our study were compared with the findings reported for 4-amino-1,2,4-triazole (ATZ). ${ }^{9}$ ATZ was found to be regioselective, giving substitution para- to the nitro group exclusively. TMH gave all possible product isomers thereby showing no selectivity but presumably greater reactivity. There was a general tendency for TMHI to yield products in which the amine substitution occurs predominantly ortho- to the nitro group although some exceptions were noted. We are currently investigating the use of more sterically crowded 1,1,1-trialkylhydrazinium halides derived from UDMH in an attempt to influence the regioselectivity of the aminating reagent: 
<smiles>[R]c1cccc([N+](=O)[O-])c1</smiles>

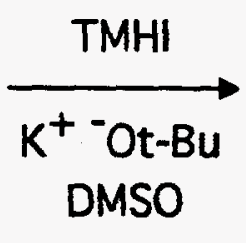<smiles>[R]c1cc(N)cc([N+](=O)[O-])c1</smiles>

Scheme 3. Amination of 3-substituted nitroaromatics.

Table 1 . Amination of 3-Substituted Nitrobenzenes

\begin{tabular}{llll}
$\mathrm{R}$ & Total Yield (\%) & position of $\mathrm{NH}_{2}{ }^{\mathrm{a}}$ & \% isomer \\
\hline $\mathrm{H}$ & 85 & 2 & 61 \\
$\mathrm{CH} 3$ & & 4 & 39 \\
& 84 & 2 & 38 \\
$\mathrm{Cl}$ & & 4 & 35 \\
& 82 & 6 & 27 \\
$\mathrm{COOH}$ & & 2 & 32 \\
$\mathrm{OCH} 3$ & 95 & 4 & 49 \\
$\mathrm{~F}$ & & 6 & 19 \\
& 66 & 4 & 71 \\
& & 6 & 29 \\
$\mathrm{I}$ & 84 & 2 & 90 \\
& & 4 & 10 \\
$\mathrm{CN}$ & 76 & 2 & 45 \\
& & 4 & 47 \\
& & 6 & 8 \\
a Relative to NO2 & & 2 & 45 \\
& & 4 & 38 \\
& & 6 & 17 \\
& & 2 & 20 \\
& & 4 & 44 \\
& & 6 & 36
\end{tabular}

\section{Starting Materials for TATB Synthesis}

This project originally began as part of demilitarization activities related to the chemical conversion of energetic materials into higher value products. 15,16 Consequently, our synthesis of TATB has been designed so that either surplus energetic materials or inexpensive, commercially available chemicals can be used to make the necessary starting materials. Several million pounds of ammonium picrate (Explosive D) are available for disposal in the USA. Ammonium picrate can be converted to 2,4,6-trinitroaniline (picramide) by the pathways shown in Scheme 4 . The reaction of picric acid with urea at elevated temperature $\left(173^{\circ} \mathrm{C}\right)$ has been reported to provide picramide in $88 \%$ yield. 17 The analogous reaction of Explosive $\mathrm{D}$ with urea to directly provide picramide has not been reported. Picramide is also readily accessible from nitration of the commercially available and relatively inexpensive 4-nitroaniline. 18

1,1-Dimethylhydrazine (unsymmetrical dimethylhydrazine, UDMH) has been used as a liquid rocket propellant. Thirty thousand metric tons of UDMH in Russia are available for disposak in a safe and environmentally responsible manner. 1.9 1,1,1-Trimethylhydrazinium iodide (mim) our VNS reagent of choice, is readity prepared through the alkylation of UDMH by methyliad 20 Alternatively, Twith can be prepared directly from hydrazine and methyl iodide. 13 


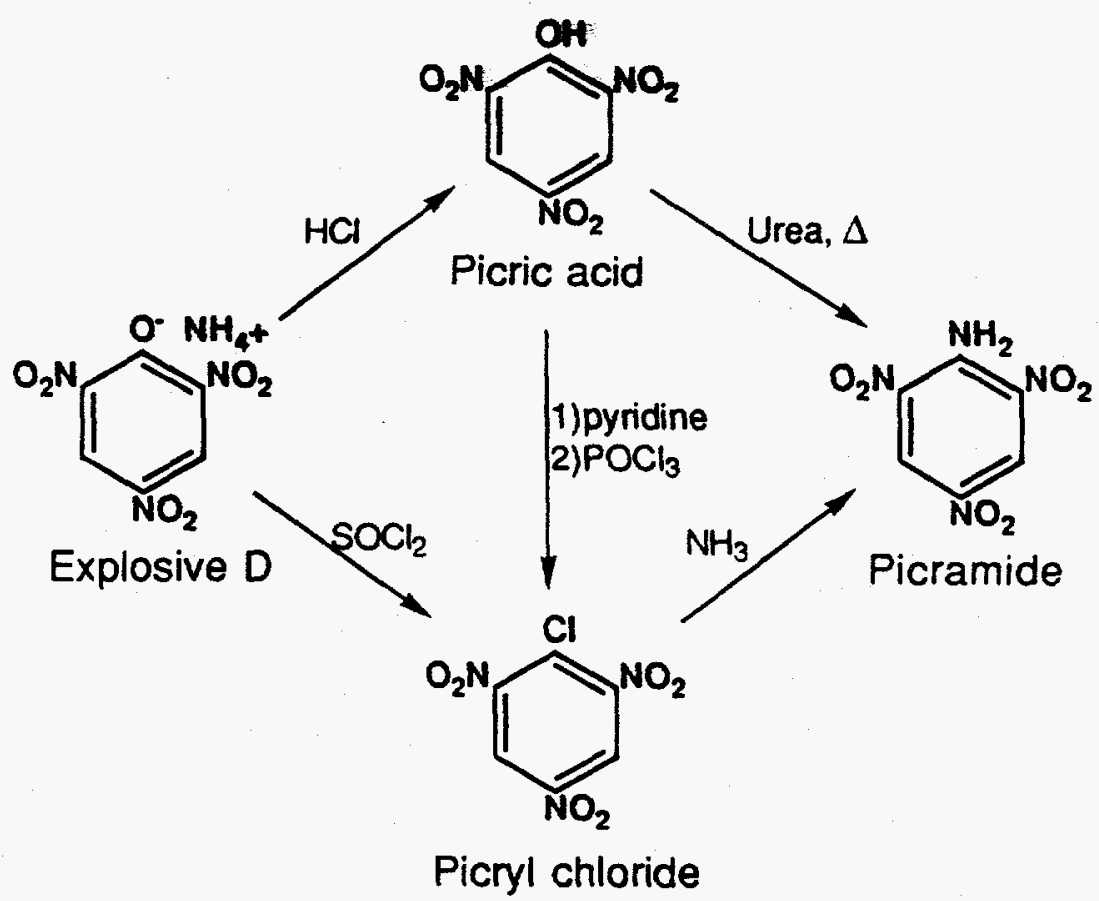

Scheme 4. Synthesis of picramide from Explosive D.

Amination of Picramide by Hydroxylamine Derivatives

We initially explored the conversion of picramide to DATB and TATB using hydroxylamine (Scheme $5, R=H$ ) and aqueous base as reported for the conversion of 4,6-dinitrobenzofuroxan (DNBF) to give 5,7-diamino-4,6-dinitrobenzofuroxan (CL-14). 21 DATB was obtained in a low yield (16\%) after removal of unreacted picramide.<smiles>Nc1c([N+](=O)[O-])cc([N+](=O)[O-])c([N+](=O)[O-])c1N</smiles>

Picramide

DATB

TATB

Scheme 5. Reaction of picramide with $\mathrm{NH}_{2} \mathrm{OR}\left(\mathrm{R}=\mathrm{H}, \mathrm{CH}_{3}, \mathrm{C}_{6} \mathrm{H}_{5} \mathrm{CH}_{2}\right)$

The replacement of aqueous base with sodium methoxide in anhydrous methanol or DMSO raised the yield of DATB from $16 \%$ to over $50 \%$. The use of alkoxy derivatives $\left(\mathrm{R}=\mathrm{CH}_{3}, \mathrm{C}_{6} \mathrm{H}_{5} \mathrm{CH}_{2}\right)$ gave exclusively DATB in $87-91 \%$ crude yields. The reaction of picramide with hydroxylamine or its O-alkyl derivatives never yielded more than trace quantities of TATB.

\section{Amination of Picramide by ATZ}

Picramide reacts with 4-amino-1,2,4-triazole (ATZ) in dimethylsulfoxide in the presence of strong base ( $\mathrm{NaOMe}$ or $\mathrm{KO} t-\mathrm{Bu})$ at room temperature $(24 \mathrm{~h})$ to yield, depending on the quantity of ATZ used, either DATB or TATB and 1,2,4-triazole (TZ) (Scheme 6).

When TMH repleces ATZ in the reaction with picramide, the reaction is complete in $3 \mathrm{~h}$ to yield DATB (70-80\%) or TATB (95-98\%) and trimethylamine (TMA) (Scheme 7). 


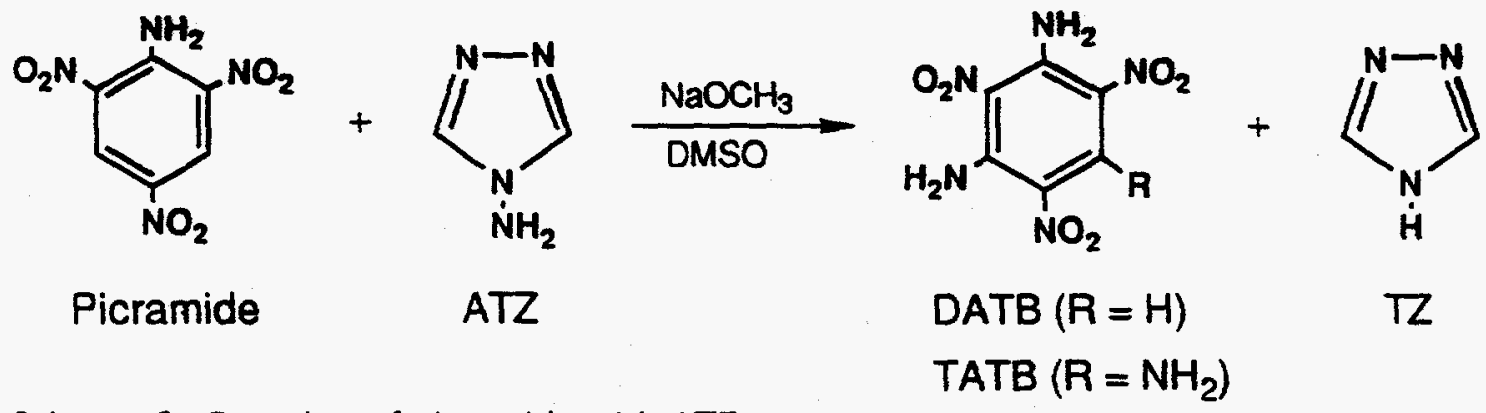

Scheme 6. Reaction of picramide with ATZ.<smiles>C[N+](C)(O)CC[I+][N+](C)(C)N</smiles><smiles>CN(C)C</smiles>

Picramide

TMHI

$$
\begin{aligned}
& \text { DATB }(\mathrm{R}=\mathrm{H}) \\
& \operatorname{TATB}\left(\mathrm{R}=\mathrm{NH}_{2}\right)
\end{aligned}
$$

TMA

Scheme 7. Reaction of picramide with TMHI.

The TMA released can be used to regenerate the TMHI that is consumed during the reaction. The reaction of TMA with chloramine $\left(\mathrm{CINH}_{2}\right)$ yields trimethylhydrazinium chloride (TMHCl) which is treated with hydroiodic acid to yield TMHI (Scheme 8), 22 The use of TMHCl for nucleophilic aminations of nitroarenes is under investigation.<smiles>C[N+](C)(N)C=CC#CCl</smiles>

\section{TMA}

$\mathrm{TMHCl}$

TMHI

Scheme 8. Conversion of TMA to TMHI.

\section{Summary}

The new synthesis of TATB that we intend to scale up from the laboratory bench to pilot plant is outlined in Scheme 9. The starting materials are relatively inexpensive and can be obtained from demilitarization programs (Explosive D, UDMH) or commercial sources (4-nitroaniline, hydrazine). We have eliminated the use of chlorinated arenes in response to environmental concerns and will recycle solvents and materials whenever possible. 23 Trimethylamine (TMA), a noxious and moderately toxic gas (bp $3^{\circ} \mathrm{C}$ ) released during the VNS reaction, will be reacted with chloramine to regenerate the TMHCl consumed in the synthesis of TATB. 


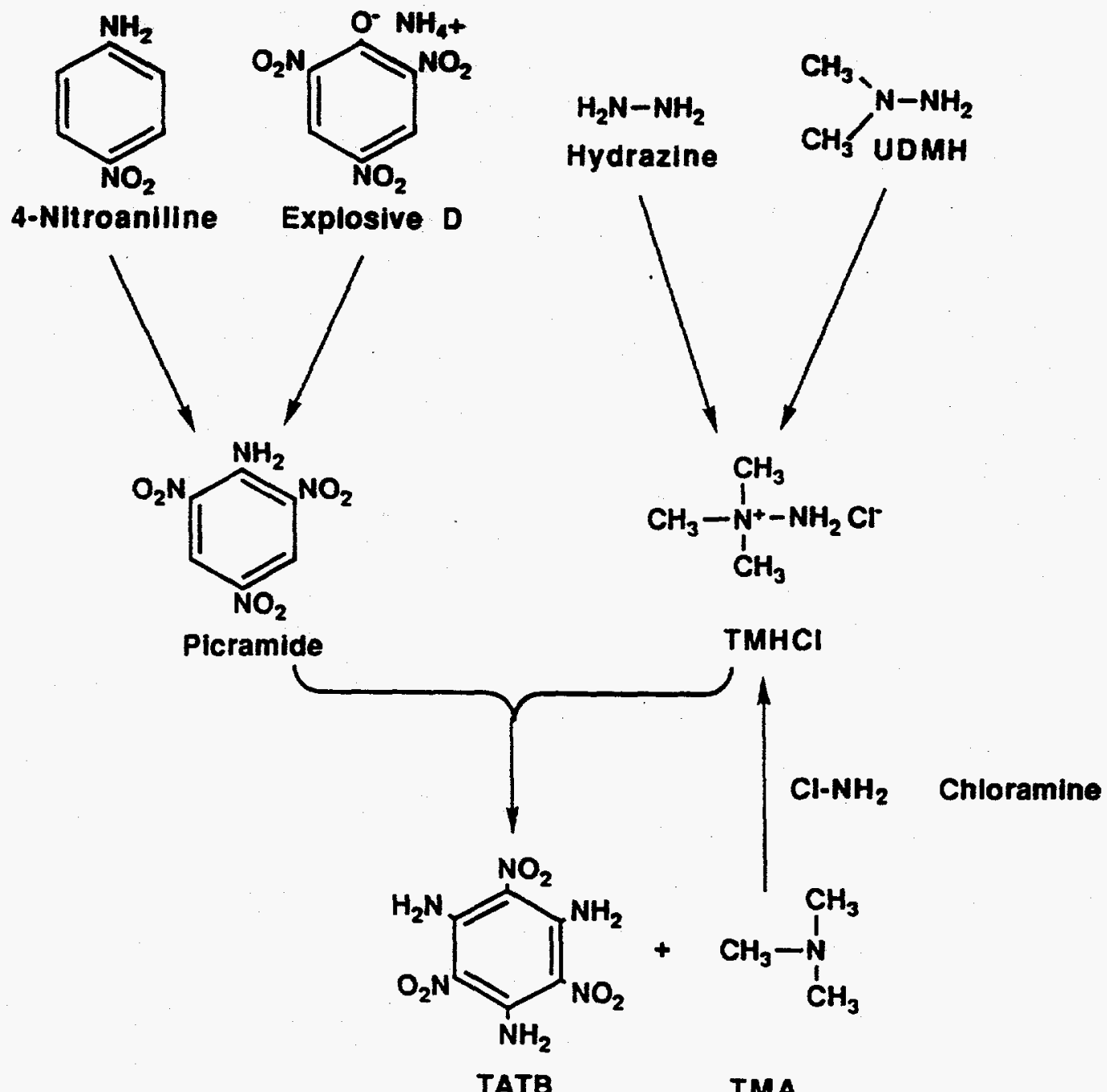

Scheme 9. Synthesis of TATB from inexpensive starting materials.

\section{References}

1. Rice, S.F. and Simpson, R.L, 1990. "The Unusual Stability of TATB: A Review of the Scientific Literature", Lawrence Livermore National Laboratory, Livermore, CA, Report UCRL-LR-103683.

2. Simpson, R.L., Energetic Materials Center, Lawrence Livermore National Laboratory, personal communication.

3. Benziger, T.M., 1981. "Manufacture of Triaminotrinitrobenzene," in Chemical and Mechanical Technologies of Propellants and Explosives, Proc. 1981 Intl. Annual Conference of ICT, Karlsruhe, Germany, pp. 491-503.

4. Benziger, T.M., 1977. Method for the Production of High-Purity Triaminotrinitrobenzene, U. S. Patent No. 4,032,377.

5. Yasuda, S. K., 1972. "Identification of 1,3,5-Triamino-2,4,6-Trinitrobenzene Impurities by Two-Dimensional Thin-Layer Chromatography," J. Chromatogr., Vol. 71, pp. 481-486.

6. Makosza, M. and Winiarski, J., 1987. "Vicarious Nucleophilic Substitution of Hydrogen," Acc. Chem. Res., Vol. 20, pp. 282-289.

7. O. N. Chupakhin, V. N. Charushin and H. C. van der Plas, 1994. Nucleophilic Aromatic Substitution of Hydrogen, Academic Press, San Diego, CA, pp. 59-66.

8. Meisenheimer, J. and Patzig, E., 1906. "Directe Einführung von Aminogruppen in den Kern aromatischer Körper", Ber., Vol. 39, pp. 2533-2542.

9. Katritzky, A.R. and Laurenzo, K. S., 1986. "Direct Amination of Nitrobenzenes by Vicarious Nucleophilic Substitution," J. Org. Chem., Vol. 51, pp. 5039-5040.

10. Makosza, M: and Bialecki, M., 1992. "Amination of Nitroarenes with Sulfenamides via Vicarious Nudeophilic Substitution of Hydrogen," J. Org. Chem., Vol. 57, pp. 4784-4785. 
11. Fischer, E, 1876. "Über aromatische Hydroximertidtungen," Ber., Vol. 9, pp. 880-891. 12. Sister, H. H. and Omietansti, G., 1957. "The Chemisthy of Quatemized Hydrazine Compounds; Chem. Rev. , Vol. 57, pp. 1021-1047.

13. Harries, C. and Haga, T., 1898. "Über die Methylienung des Hydrazinhydrats," Ber. , Vol. 31, pp. 56-64.

14. Pagoria, P. F., Mitchell, A. R. and Schmidt, R. D., 1996. "1,1,1-Trimethylhydrominium: lodide (TMHI): A Novel, Highly Reactive Reagent for Aromatic Amination via Vicarious Nucloophilic Substitution (VNS)", J. Org. Chem., in press.

15. Pruneda, C. O. , Mitchell, A. R. and Humphrey, J. 1993. "Reusing the High Explosives from Dismantled Nuclear Weapons," Energy and Technology Review, Lawrence Livermore National Laboratory, Livermore, CA, UCRL-52000-93-11-12, pp.19-26.

16. Mitchell, A. R. and Sanner, R. D., 1993. "Chemical Conversion of Energetic Materials to Higher Value Products," in Energetic Materials- Insensitivity and Environmental Awareness, Proc. 24th Intl. Annual Conference of ICT, edited by Ebeling, H., Karlsruhe, Germany, pp. 38:1-38:6.

17. Spencer, E. Y. and Wright, G. F., 1946. "Preparation of Picramide," Can. J. Research, Vol. 24B, pp. 204-207.

18. Holleman, A. F., 1930. "1,3,4,5-Tetranitrobenzene," Rec. trav. chim., Vol. 49, pp. 112-120.

19. Chemical and Engineering News, May 8,1995, p.21.

20. Westphal, 0., 1941. "Uber die Alkylierung des Hydrazins," Ber., Vol. 74, pp. 759-776.

21. Norris, W. P. and Chafin, A. P., 1985. "CL-14, A New Dense, Insensitive, High Explosive," Naval Weapons Center, China Lake, CA, NWC TP 6597 (publication UNCLASSIFIED).

22. Omietanski, G. M. and Sister, H. H., 1956. "The Reaction of Chloramine with Tertiany Amines. 1,1,1-Trisubstituted Hydrazinium Salts," J. Am. Chem. Soc., Vol. 78, pp. 1211-1213.

23. Graedel, T. E. and Allenby, B. R., 1995. Industrial Ecology, Prentice Hall, Englewood Cliffs, NJ, pg. 412. 